
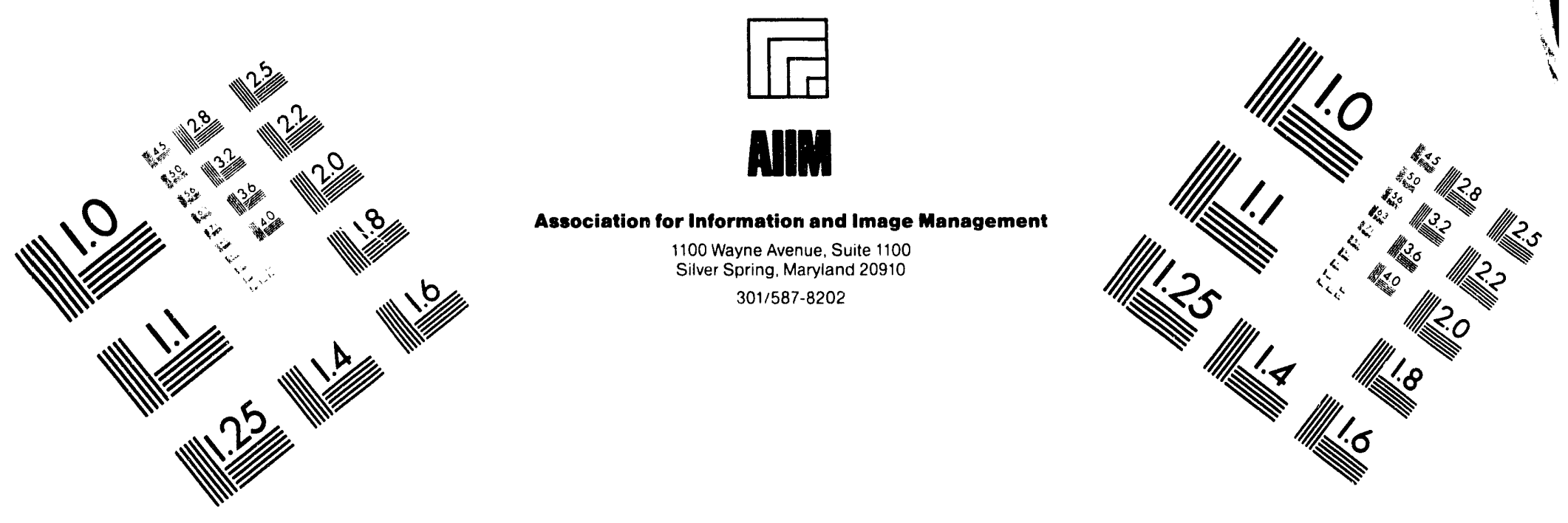

\title{
Centimeter
}

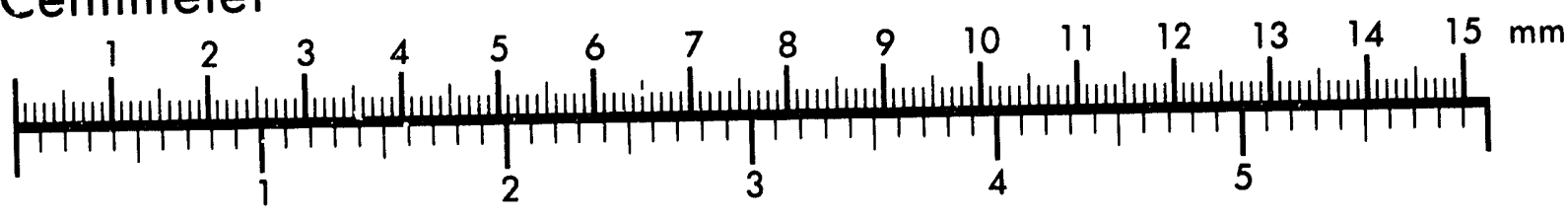
Inches
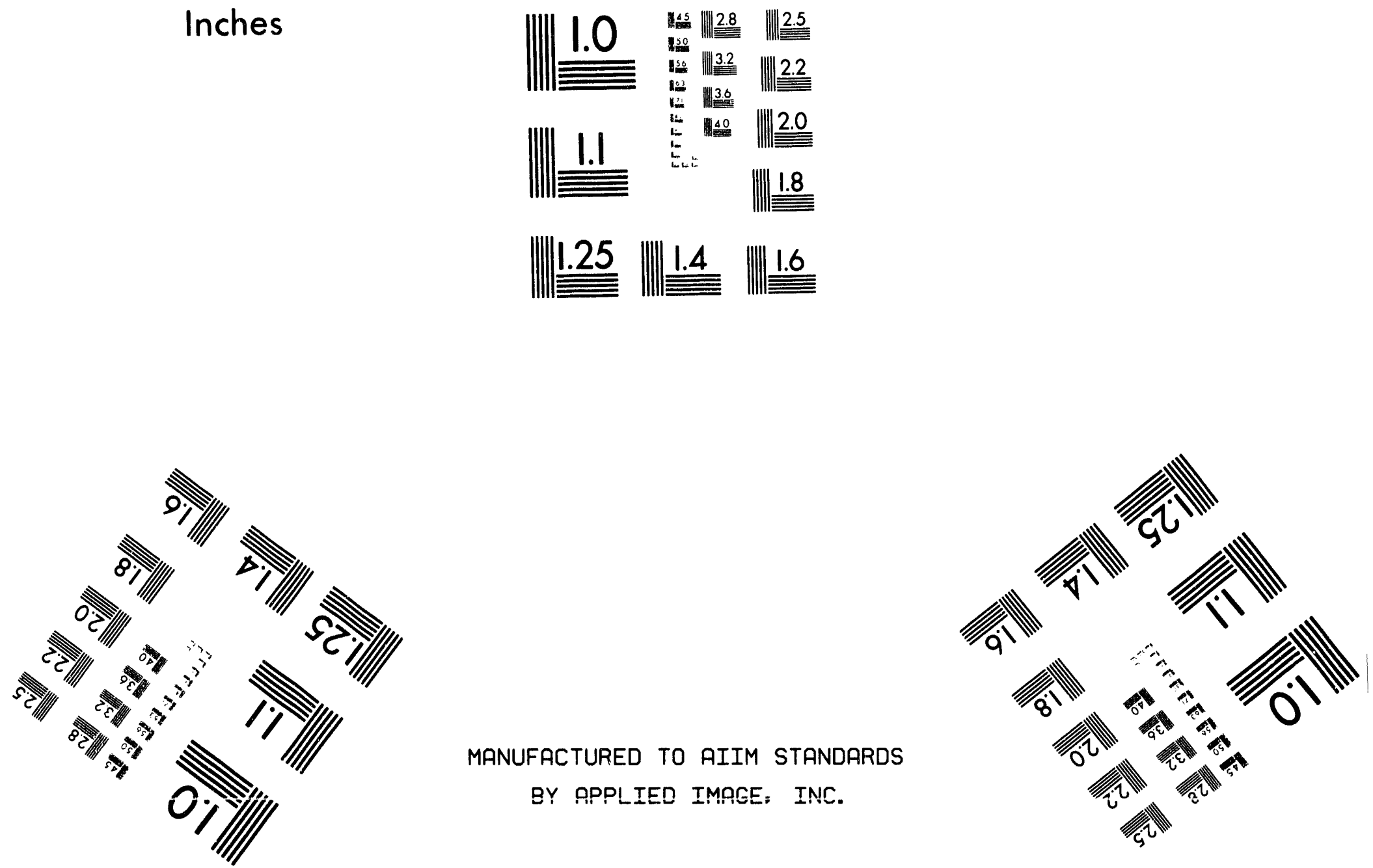

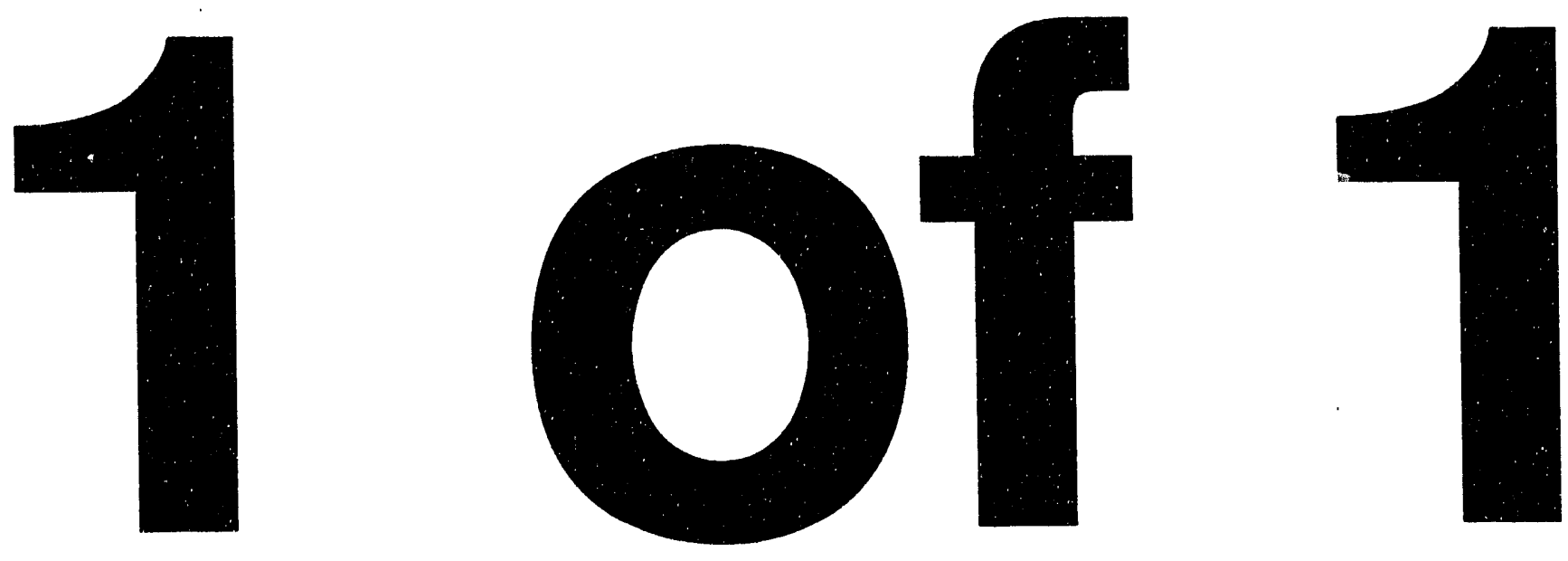


\author{
CRITICAL TECHNOLOGIES FOR REACTORS USED \\ IN NUCLEAR ELECTRIC PROPULSION \\ by \\ S. K. Bhattacharyya \\ Argonne National Laboratory \\ 9700 S. Cass Avenue \\ Argonne, IL 60439
}

\title{
DISCLAIMER
}

\begin{abstract}
This report was prepared as an account of work sponsored by an agency of the United States Government. Neither the United States Government nor any agency thereof, nor any of their employees, makes any warranty, express or implied, or assumes any legal liability or responsibility for the accuracy, completeness, or usefulness of any information, apparatus, product, or process disclosed, or represents that its use would not infringe privately owned rights. Reference herein to any specific commercial product, process, or service by trade name, trademark, manufacturer, or otherwise does not necessarily constitute or imply its endorsement, recommendation, or favoring by the United States Government or any agency thereof. The views and opinions of authors expressed herein do not necessarily state or reflect those of the United States Government or any agency thereof.
\end{abstract}

Paper to be submitted to the:

American Nuclear Society

National Critical Technologies Embedded Topical Meeting

June 23, 1993

San Diego, CA

Send Correspondence to:

Samit K. Bhattacharyya

Engineering Physics Division

Argonne National Laboratory

9700 S. Cass Avenue, Bldg. 207

Argonne, Illinois 60439

Phone: (708) 252-3293

FAX: (708) 252-4007

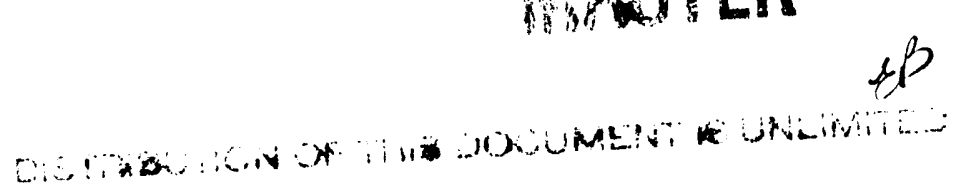




\section{Critical Technologies for Reactors used in Nuclear Electric Propulsion}

S. K. Bhattacharyya Argonne National Laboratory

9700 S. Cass Avenue

Argonne, IL 60439

Nuclear Electric Propulsion (NEP) Systems are expected to play a significant role in the exploration and exploitation of space. Unlike Nuclear Thermal Propulsion (NTP) Systems, in which the hot reactor coolant is directly discharged from nozzles to provide the required thrust, NEP systems include electric power generation and conditioning units that in turn are used to drive electric thrusters. These thrusters accelerate subatomic particles to produce thrust. The major advantage of NEP systems is the ability to provide very high specific impulses $(-5000 \mathrm{~s})$ that minimize the requirement for propellants. In addition, the power systems used in NEP could provide the dual purpose of also providing power for the missions at the destination. This synergism can be exploited in shared development costs. The NEP systems produce significantly lower thrust than NTP systems and are generally more massive. Both systems have their appropriate roles in a balanced space program.

The technology development needs of NEP systems differ in many important ways from the development needs for NTP systems because of the significant differences in the operating condition of the systems. NEP systems require longlife reactor power systems operating at power levels that are considerably lower than those for NTP systems. In contrast, the operational lifetime of NEP system (years) is orders of magnitude longer than the operational lifetime of NTP systems (1000's of seconds). Thus the critical issue for NEP is survivability and reliable operability for very long times at temperatures that are considerably more modest than the temperatures required for effective NTP 
operations, but generally much higher than those experienced in terrestrial reactors.

Utilization of reactor power systems for space exploration and exploitation requires a significant technology development effort. Considering just the reactor and directly associated components, the following technology development items are the most important.

Robust fuel with high temperature, high burnup capability

- A broad range of lightweight high temperature materials for use in various parts of the power system

- Highly reliable, fault tolerant control systems with considerable diagnostic and trouble shooting capability

- Radiation hardened, high temperature electronics

- Innovative reactor and shield concepts

- Microgravity effects on fluid flow

Development of these technologies will require early start relative to the planned development time because of the long times involved in this effort. This is best illustrated by a few examples. Design of innovative reactors and shields and robust control systems will require the use of detailed critical experiments and their analyses. Results of these evaluations need to be fed back into the design since tight optimizations are necessary to minimize excess mass of flight systems. The availability of facilities for detailed mock-ups of the core and shield design is essential. Similarly, the development of advanced fuel with high temperature and high burnup capability is a complex endeavor and requires development of manufacturing characterization and testing facilities. Long-term in-reactor tests of the fuel at the appropriate temperature and environmental conditions need to be undertaken to test for burnup capability consistent with the desired long lives. The availability of reactor test facilities with the 
appropriate neutron spectrum and supporting capabilities (e.g. post irradiation examination) for these periods of time is an issue. As a general rule, thermal neutron spectrum reactors provide the best power systems for low powers ( $50 \mathrm{KWe}$ or less) while fast spectrum reactors are preferred for higher power systems. Thus, different kinds of reactors are needed for the testing of NEP reactors. A full-scale ground test is generally required for systems to be flown in space. For NTP systems, for example, such a test will be necessary. The present thinking on NEP systems is that a fully integral ground test will not be performed--rather the individual subcomponents will be tested separately. The point is that a full reactor system test will be required and for the power levels of likely interest (a few KWe to several MWe) this involves major site preparation. Once again an early start is essential.

The fundamental principle of operability of reactors in space has been proven by the US SNAP-1OA flight and the numerous Russian reactor flights. The Russian TOPAZ reactor and the US SP-100 reactor have produced hardware of recent vintage that are applicable to initial NEP missions. The TOPAZ reactor is a 5 KWe, $\mathrm{UO}_{2}$ fueled, $\mathrm{ZrH}$ moderated, NaK cooled thermal spectrum system. The system has been space tested for periods of up to one year. Various technology development steps are currently in progress to allow for increased power and longer lifetimes. The SP-100 project has developed UN fuel for seven year operation (burnup tested in EBR-II) and detailed reactor and system designs. A detailed critical experimental program has been completed and several najor hardware components have been developed and tested.

Thus, while significant technology development still needs to be done to reach the longer teria goals for NEP reactors, there is existing, proven technology on which to base such development and with which initial NEP systems can be tested. Significant technology transfer can be effected from the 
considerable work done in terrestrial reactor development. Development of the critical technologies associated with NEP systems will not only allow us to maintain our leadership in space, but also many of the developments will find applications in the commercial sector to help in US competitiveness. 

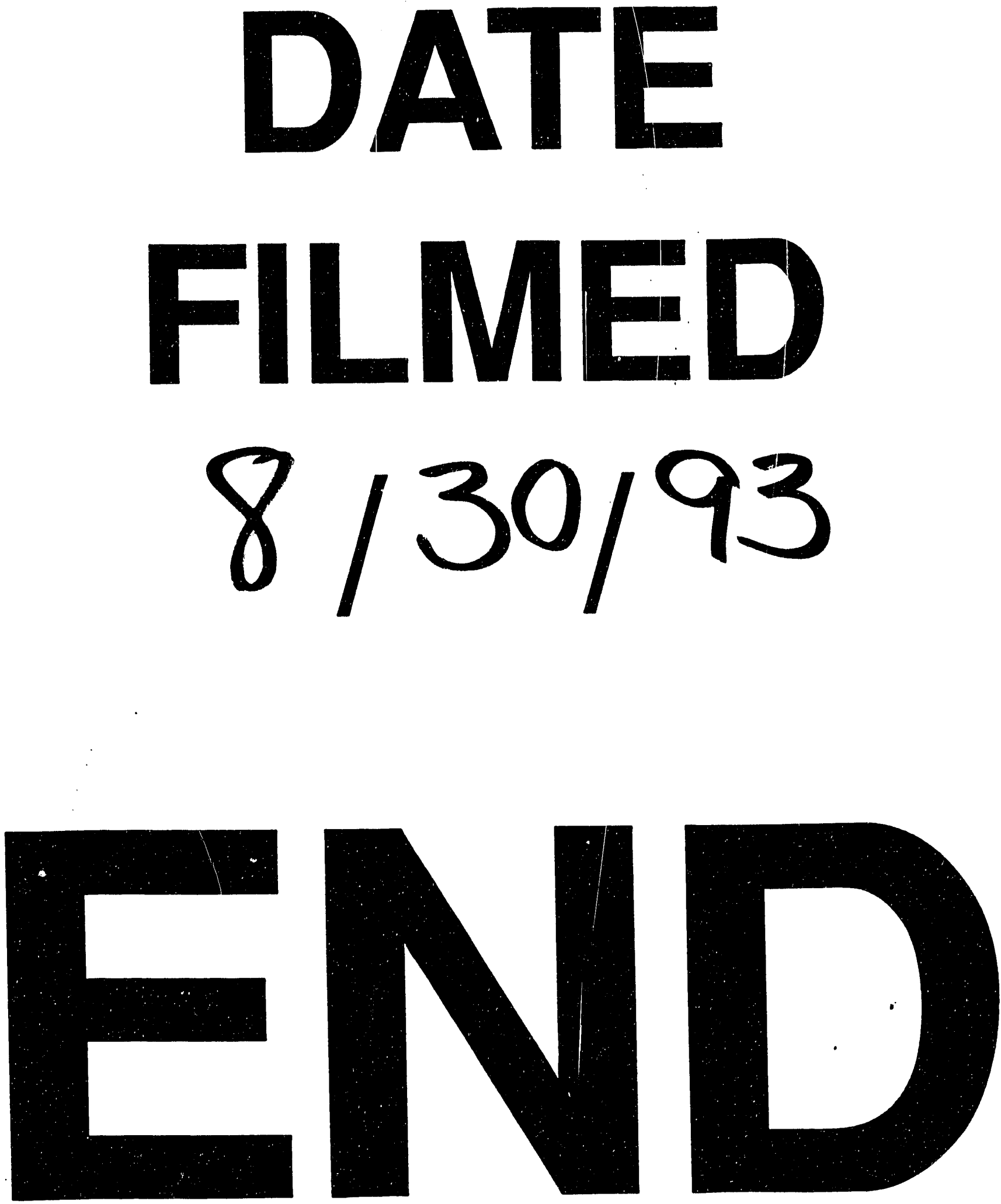
